\title{
UMA PROPOSTA DISCURSIVA DE LEITURA NAS CONDIÇÕES DO PROFLETRAS: NO JOGO ENTRE PARÁFRASE E POLISSEMIA
}

\author{
A DISCURSIVE PROPOSAL FOR READING UNDER THE PROFLETRAS CONDITIONS: IN THE \\ GAME BETWEEN PARAPHRASE AND POLYSEMY
}

\author{
Luciana Cristina Ferreira Dias Di Raimo ${ }^{1}$ \\ ${ }^{1}$ Universidade Estadual de Maringá (UEM), Maringá, PR, Brasil \\ Icfddraimo@uem.br
}

Recebido em 10 out. 2019

Aceito em 5 nov. 2019

Resumo: Neste artigo, apresentamos aspectos teórico-práticos concernentes a uma proposta discursiva de leitura de cunho discursivo desenvolvida com mestrandos do Profletras, na disciplina "Linguagem, práticas sociais e ensino". Buscando movimentar noções da Análise de discurso, bem como trazer um exemplar de uma possível abordagem discursiva do texto e dos sentidos, são mobilizados, neste artigo, num jogo entre teoria e prática, os conceitos de condições de produção, os processos de paráfrase e polissemia e efeito metafórico. A proposta teve como objetivo apresentar possíveis encaminhamentos para o texto e problematizar algumas questões pertinentes ao ensino da leitura de língua portuguesa, tais como a evidência dos sentidos, a contradição e a equivocidade. Justamente, a filiação à Análise de discurso nos permitiu abrir oportunidades para que questionássemos como a sala de aula pode ser um evento interpretativo, isto é, um espaço em que haja possibilidades de efetivação de autoria por parte de alunos e (também) de professores. Com efeito, ao investir n(os) movimentos dessa articulação entre Análise de discurso e ensino, como pesquisadores, professores de língua portuguesa e sujeitos de linguagem, não somente movimentamos propostas, abordagens e gestos de leitura, como também fomos movimentados pela/na Análise de discurso, em uma sedutora aventura marcada por tensões e encantamentos.

Palavras-chave: Leitura. Paráfrase e polissemia. Profletras.

Abstract: In this paper, we present methodological and theoretical aspects concerning with a discursive reading proposal focused on master students from Profletras, in the discipline "'Linguagem, práticas sociais e ensino". In an attempt to move notions of Discourse Analysis, as well as to bring an example of a possible discursive approach to text and the meaning, in this article, the concepts of production conditions, the processes of paraphrase and polysemy and metaphorical effect are mobilized in the game between theory and practice. The proposal aims to present possible referral to the text and discuss some issues related to the Portuguese language of reading instruction such as evidence of the senses, the contradiction and the equivocity. Precisely, the affiliation to the Discourse Analysis has allowed us to open opportunities to think about how the classroom can be an interpretive event, that is, a space in which there is a possibility of authorship by students and (also) teachers. Indeed, by investing in the movements of this articulation between Discourse Analysis and teaching, such as researchers, teachers of Portuguese language and language subjects, we not only moved proposals, approaches and reading gestures, but we were also moved by discourse Analysis, in a seductive adventure marked by tensions and enchantments.

Keywords: Reading. Paraphrase and polysemy processes. Profletras.

\section{GESTOS INICIAIS}

Considerando as condições de produção do Profletras (mais especificamente da unidade local da Universidade Estadual de Maringá/PR), neste presente trabalho, 
a tentativa é a de trazer à cena uma prática de leitura que foi apresentada a alunos e alunas do Profletras, na disciplina "Linguagem, práticas sociais e ensino". Nesse caso, tal abordagem de leitura tencionou ilustrar uma possível movimentação de conceitos e práticas que poderiam ser implementados em sala de aula à luz da Análise de discurso de matriz pecheuxtiana.

De um ponto de vista aplicado, trabalhar entre conceitos da Análise de Discurso e reflexões sobre a prática de sala é uma experiência marcada tanto por retomadas quanto por deslocamentos de práticas/dizeres estabilizados no espaço da escola.

Com efeito, ao contemplar práticas de linguagem em sala de aula, sob um ponto de vista discursivo, é relevante ser consequente com uma noção de sujeito que não é fonte nem origem do dizer, de uma linguagem opaca e transparente e de uma noção de leitura aberta à possibilidade de o sentido ser outro. Desse modo, o movimento de apresentar uma abordagem discursiva de leitura de materialidades diversas demandou que fossem deslocadas ilusões ligadas a uma leitura inequívoca, bastante presente na escola e atrelada à literalidade do sentido.

Assim sendo, levando às consequências a imbricação de diferentes linguagens na formulação e constituição dos sentidos, este trabalho de movimentar a AD em uma disciplina do Mestrado Profissional em Letras nos possibilitou tanto explorar materialidades diversas em seus efeitos de sentidos quanto compreender como a Análise de discurso pode abrir espaços para que cada professor e professora (re)pensasse a linguagem, os sentidos, o sujeito de uma outra forma em uma tensa e sedutora relação entre a repetição e o deslocamento, entre a unidade e a dispersão.

\section{ANCORAGEM TEÓRICO-METODOLÓGICA}

Num primeiro momento, produzir um gesto de reflexão sobre o campo da Análise de discurso na relação com práticas de linguagem na escola, especificamente na disciplina "Linguagem, práticas sociais e ensino", da matriz curricular do Profletras, nos exigiu problematizar em que medida o ensino de língua portuguesa pode estabelecer relações com as contribuições epistemológicas da Análise de discurso em meio a fronteiras disciplinares. 
Iniciamos esta reflexão, trazendo Maldidier (2003), para quem pensar na história da Análise do Discurso na França é vislumbrar uma "aventura teórica do discurso" (MALDIDIER, 2003, p. 15) na qual Pêcheux constrói, amadurece e retifica uma teoria. Assim, no desenvolvimento da teoria do discurso, um ponto nodal desde o início da $A D$ e nos desdobramentos posteriores para Pêcheux diz respeito ao fato de que:

o discurso não pode ser tomado como fala, um ato individual. O discurso deve ser tomado como um conceito que não se confunde nem com o discurso empírico sustentado por um sujeito, nem com o texto, um conceito que estoura qualquer concepção comunicacional de linguagem (MALDIDIER, 2003, p. 21)

Desse modo, o gesto de problematizar pontos nodais concernentes à Análise de discurso na relação com a leitura em sala de aula trouxe como desafio, neste percurso empreendido, um movimento de deslocamentos de sentidos estabilizados no que concerne às noções de sujeito, língua e sala de aula.

Tomando por base que a Análise de discurso, enquanto dispositivo teórico e analítico, constrói-se no entremeio com os campos que a constituem, a leitura discursiva consequentemente sofre efeitos das concepções que a Análise de discurso desloca, revê, a saber: a língua para Pêcheux não é mais um sistema de signos, nem um objeto transparente que produziria um único sentido mas sim vista pela exterioridade; o materialismo histórico nos traz a premissa de que os homens fazem a história que lhes é possível; o atravessamento da Psicanálise descentra o sujeito todo poderoso, fonte intencional de um dizer.

Assim sendo, nesse vai e vem entre a sala de aula de leitura e a Análise de discurso, emergiu a seguinte pergunta mobilizadora: em que medida questões epistemológicas da Análise de discurso, uma disciplina que se constrói no entremeio de vários campos, têm consequências para práticas de leitura nas condições de produção da escola?

Um primeiro ponto que fora problematizado diz respeito ao fato de que Pêcheux, em meio a um contexto de triunfo do estruturalismo, nos anos de 50 e 60, vai questionar uma abordagem meramente linguística do texto, que não contempla o sujeito, o social e o histórico como constitutivos do funcionamento da linguagem. Assim, como consequência, o filósofo reformula a categoria língua/fala para ampliá- 
la à relação língua e discurso. Desse modo, constrói-se um novo objeto que não é mais a língua, mas o discurso- que não pode ter tomado como sinônimo de texto, pois, segundo Pêcheux (1990, p. 79), "é impossível analisar um discurso como um texto, é necessário referi-lo ao conjunto de discursos possíveis". Nesse sentido, "Michel Pêcheux constitui o discurso como uma reformulação da fala saussuriana, desembaraçada de suas implicações subjetivas" (MALDIDIER, 2003, p. 22).

De fato, é preciso considerar que a noção de língua para Pêcheux não é tomála como um sistema de signos ou ainda como um objeto transparente "controlado" por um sujeito intencional. Com efeito, é necessário investir em uma concepção de língua enquanto produção social, considerando a exterioridade como constitutiva e um sujeito que enuncia em sua individualidade, mas que se inscreve seu dizer em uma formação discursiva ou outra para significar.

Dessa forma, se, no estruturalismo, o sujeito e a situação são postos de lado, a Análise de discurso materialista define discurso como "efeito de sentidos entre interlocutores" (PÊCHEUX, 1990, p. 82), o que nos leva a defender o papel decisivo das condições de produção contra a evidência do sentido como conteúdo e do sujeito (de linguagem) como todo poderoso.

Assim, o conceito de condições de produção foi fundamental para que reforçássemos a necessidade de olhar para a exterioridade, considerando as condições sócio-históricas de um texto não de forma secundária, mas sim como constitutivas da sua própria significação. Nas palavras de Hashiguti (2009, p. 19),

se os textos mudam de sentido com as condições de produção, a leitura pensada em relação à literalidade, a uma possível transparência da linguagem, é uma ilusão: a leitura é uma prática que pressupõe a história e o trabalho de memória do sujeito.

Justamente, interessou-nos pensar a respeito desse movimento do sujeito de linguagem que ao significar, se significa e nunca é indiferente aos percursos de sentido, processos discursivos afirmados, negados, legitimados acerca de qualquer questão posta. Assim sendo, somos muitas vezes pegos pela/na linguagem. Estamos falando aqui desde as atividades mais banais e prosaicas do dia-a-dia, como Orlandi explica que dizem respeito ao uso mais aparentemente cotidiano dos signos. $E$ isso também se relaciona às práticas de linguagem em sala de aula, no 
modo como significamos e somos significados nas condições de ensinoaprendizagem.

Foi salutar trazer elucubrações relativas ao fato de o sujeito se submeter à língua tomada como sistema. O sujeito não é livre para dizer o que quer tampouco fazer o que quer. Temos, nas condições de produção do sistema capitalista, um sujeito de direitos e de deveres, com vontade e com responsabilidade. Eis a noção do assujeitamento. Na forma-sujeito capitalista, o sujeito deseja ter a liberdade de fazer o que quer, ao mesmo tempo em que se submete, o que revela uma contradição do Capitalismo: funcionamos na ilusão da liberdade $e$ da responsabilidade por nossos atos e ao mesmo tempo nos submetemos aos sentidos, às condições materiais, ao próprio sistema da língua.

Dessa forma, trazer para o debate este fragmento da autoria de Pêcheux (1988, p. 266) "a forma-sujeito do discurso, na qual coexistem indissociavelmente interpelação, identificação e produção de sentido, realiza o non-sense da produção do sujeito como causa de si sob a forma da evidência primeira" tanto nos permitiu estabelecer outras possíveis relações de cunho teórico entre Análise de discurso e ensino, quanto avançar em termos de percurso de leitura.

Estávamos diante de uma interessante compreensão acerca da relação sujeito e linguagem. O indivíduo é interpelado em sujeito pela ideologia para que se produza o dizer, mas é interessante assinalar que essas evidências que dão ao sujeito a realidade como sistemas de significações percebidas, experimentadas apagam o fato de que o sentido é construído, de que o sujeito se constitui em processos históricos, sociais. A ideologia fornece ao próprio sujeito as evidências e assim o caráter material dos sentidos é apagado. Ou seja, negamos a interpretação ao mesmo tempo em que interpretamos.

Deslocando uma visão cartesiana de sujeito todo poderoso e dono de suas vontades, o gesto de trazer ao debate o atravessamento da Psicanálise que descentra o sujeito tomado como fonte intencional foi um desafio. Dessa maneira, buscamos nos ater a Pêcheux que problematiza justamente uma noção de sujeito livre, fonte intencional de um sentido, na medida em que "o sujeito se constitui pelo 'esquecimento' daquilo que o determina” (PÊCHEUX, 1988, p. 163).

Assim, foi preciso problematizar a categoria de sujeito marcada pela noção de assujeitamento, isto é, conforme Leandro Ferreira (2003, p. 43), "ser assujeitado 
significa antes de tudo ser alçado à condição de sujeito, capaz de compreender, produzir e interpretar sentidos", bem como pelo atravessamento do inconsciente que marca um sujeito descentrado, afetado pela ferida narcísica e pela ilusão da completude.

À medida que as aulas desenvolviam-se, foi importante estabelecer que pensar a leitura discursiva é justamente tomá-la como uma prática de produção de sentidos e questionar a ilusão de que os sentidos nascem em nós ou que o sentido é algo já posto, quando, na verdade, eles falam em nós. Isto pôde ser explicado em virtude de que para que as palavras façam sentido, é preciso que elas já tenham sentido. Além disso, foi produtivo considerar também as possibilidades de (des)estruturação desses sentidos, desestabilizando o já-dito, abrindo-se para o equívoco e a polissemia.

Ademais, ficou bastante marcado aos alunos/alunas o fato de que, de um ponto de vista discursivo, o sentido não está preso às palavras, mas precisa ser tomado a partir das posições em jogo em uma dada conjuntura ou da inscrição do dizer em uma dada formação discursiva. Em termos de definição, a formação discursiva se coloca como "o que pode e deve ser dito (articulado sob a forma de uma arenga, um sermão, um panfleto, uma exposição, um programa etc.) a partir de uma posição dada numa conjuntura" (PÊCHEUX, 1988, p. 160-161). Segundo Pêcheux (1988), o sentido de uma palavra, expressão ou proposição não existe em si mesmo, mas é determinado pelas posições ideológicas que estão em jogo no processo sóciohistórico no qual as palavras, expressões e proposições são produzidas. Assim, "as palavras, expressões, proposições etc., mudam de sentido segundo as posições sustentadas por aqueles que as empregam" (PÊCHEUX, 1988, p. 160).

Com base em Lagazzi (2011), foi salutar ressaltar que a Análise do Discurso compreende a leitura de maneira muito diferente daquela pela qual ela é normalmente entendida na escola, espaço no qual o objetivo é determinar o que o autor quis dizer, extraindo o conteúdo do texto. Isso não significa que o conteúdo seja ignorado pela Análise do Discurso, mas sempre diremos que um texto pode receber diferentes interpretações.

Da mesma forma que um texto se oferece a diferentes interpretações na relação com diferentes leitores, também um mesmo leitor poderá se significar em diferentes interpretações frente a um mesmo texto, quando em diferentes condições 
de produção. Buscamos trabalhar que, balizados pela perspectiva discursiva, os sentidos são efeitos que se produzem sob determinações históricas, por isso não podemos deixar de perguntar pelas condições para que algo seja dito de uma determinada maneira para determinado(s) interlocutor(es) em um dado contexto sócio-histórico.

A leitura, além disso, em sua dimensão da sala de aula, não pode ser tomada como prática meramente atrelada a técnicas ou estratégias que serviriam a todos e quaisquer leitores. Pensar a leitura discursivamente implica justamente, conforme Orlandi (2012, p. 12), a (im)possibilidade de conceber:

a) um autor onipotente, cujas intenções controlassem todo percurso de significação do texto; b) a transparência do texto, que diria por si toda (e apenas uma) significação; c) um leitor onisciente, cuja capacidade de compreensão dominasse as múltiplas determinações de sentido que jogam em um processo de leitura;

\section{UMA ABORDAGEM DISCURSIVA DE TEXTUALIDADES DIVERSAS}

Nesta seção do artigo, serão apresentados o que denominamos como "momentos de construção de uma abordagem discursiva da textualidade" em aulas de leitura.

Compreendendo que, para a Análise de discurso de matriz pecheuxtiana, há que se pensar em um vai e vem entre o material e os conceitos teóricos, desse modo, se para o analista em AD, há o engendramento de um movimento de ir e vir (da teoria para a análise e/ou vice-versa), pois acreditamos que estar no espaço entre (da relação discurso e ensino) também nos exige, tendo em vista a abordagem de um texto (seja verbal, visual ou constituído na imbricação de diferentes linguagens), um movimento pêndulo de vai e vem entre a análise deste texto (o material a ser trabalhado em sala de aula) e a sugestão de práticas de leitura e/ou escrita em língua portuguesa.

Assim sendo, um conceito que é demandado em uma análise prévia de um material é a noção de condição de produção do discurso tomada num sentido micro (a situação imediata) e macro - as condições sócio-históricas mais amplas nas quais se faz valer a memória do dizer tomada como resgate/retomada de um dizer e ao mesmo tempo possibilidade de deslizamentos em/para novos sentidos e inscrição em um outro discurso. 


\subsection{Direcionamentos para aulas de leitura}

Para que os alunos e alunas da disciplina "Linguagem, práticas sociais e ensino" pudessem formular seus trajetos de leitura e escrita, à luz da Análise de discurso e implementar práticas de linguagem, no espaço da sala de aula, busquei problematizar nas aulas o que designei como "momentos de uma prática de leitura e/ou escrita".

Desse modo, foi salutar dar consequência ao fato de que o conceito de discurso implica um percurso. O gesto de abordar um texto demandou justamente movimento, uma relação de sentidos.

\section{MOMENTO 1: EM MEIO ÀS CONDIÇÕES DE PRODUÇÃO DE LEITURA}

Acreditamos que um primeiro conceito que precisa ser mobilizado em toda e qualquer prática de leitura são as condições de produção e circulação de um texto. Tendo em vista a produtividade do conceito de condições de produção, foram trazidas à baila as noções de condições imediatas, considerando o espaço de formulação do texto, isto é, da linearidade do dizer, em que podemos notar se há um efeito fecho, coesão e coerência e de condições mais amplas. Desse modo, foram sugeridos alguns movimentos iniciais com base na leitura do texto que segue:

Tomando por base o texto acima, foram sugeridas possibilidades de intervenção em sala de aula conforme seguem:

- Levantamento das práticas de leituras que os sujeitos-alunos da escola realizam (leitura no impresso, na tela, que materiais que eles/elas leem, que temas são interessantes);

- Levantamento das histórias de leituras dos alunos e alunas.

Ao examinar as condições de produção de um texto em que a memória faz valer as condições sócio-históricas mais amplas (a memória do dizer), foi trabalhado com o texto $A$ carne, da autoria de Luis Fernando Veríssimo, tendo em vista os sentidos postos em funcionamento. Nesse caso, o enunciado "carne fraca", nome da 
Operação da Polícia Federal tanto pode significar o produto "carne" quanto reverberar o enunciado bíblico "a carne é fraca".

O escândalo da carne- carne adulterada ou estragada, frango com papelão, produtos cancerígenos para disfarçar a validade vencida- produziu uma série de textualizações, quer na imprensa, quer nas redes sociais, considerando os riscos desses produtos para a saúde dos consumidores, os prejuízos no setor das importações e a desmoralização do Brasil. Além disso, há que se destacar a indignação manifestada em relação a mais um esquema de fraudes e corrupção também denunciado. Assim, na abordagem de um texto, em termos metodológicos, foi produtivo pensar tanto na situação imediata do escândalo (a operação em si) quanto nas condições sócio-históricas que convocam um já dito (já-lá), isto é, tudo que já foi dito sobre outros esquemas de corrupção e fraudes também denunciados e investigados no Brasil.

Tal investimento nas condições de produção foi relevante no sentido de construir uma compreensão acerca do papel da exterioridade de todo e qualquer texto. As condições de produção foram vistas não como mera situação, mas como constitutivas dos sentidos no/pelo texto.

Assim, pudemos contemplar a retomada de um dizer e a produção de deslizamentos em/para novos sentidos e inscrição em outro discurso. Tal movimento não só encantou os alunos/alunas, como também os inspirou a pensar perguntas/práticas de leitura com base nos conceitos de condições de produção, paráfrase/polissemia e efeito metafórico.

Essas práticas iniciais de reflexão sobre as possibilidades de trabalho com a AD foram relevantes por permitirem uma necessária apropriação da noção de condições de produção. Com efeito, foi de suma relevância levar em consideração que os sujeitos, nesse caso professores e alunos, têm histórias de leituras (um percurso nem sempre coincidente) e o objeto a ler, por sua vez também, tem suas histórias de leitura. Foi interessante trazer aos professores/alunos/as do Profletras que uma aula de leitura discursiva demanda também estabelecer conexões entre as condições de produção da leitura do texto a ser lido (formas de circulação, a formulação/textualização, sua relação com outros textos) e a história de leitura dos leitores (sua trajetória como sujeitos de linguagem). 
Nesse caso, foi relevante trazer aos alunos e alunas uma reflexão sobre as (im)possibilidades de efetivação da autoria em práticas de leitura. Por que muitas vezes o nosso estudante responde o que o professor quer ouvir? Ou ainda por que há sempre uma única possibilidade de autoria que advém do livro didático ou da voz do professor? Em que medida algumas práticas mobilizam tantos os alunos (produção de vídeos, teatros, jornal da escola, entre outros)? O que é "ser autor"?

De fato, foi muito produtivo insistir que devemos "criar reais espaços interpretativos nos quais os alunos se inscrevam no interdiscurso, criando sítios de significância e, portanto, historicizando seus sentidos e colocando-se ativo no funcionamento da linguagem" (PFEIFFER, 2003, p. 103). Dessa maneira, o sujeitoaluno, mesmo não estando na origem do dizer, precisa sentir-se seguro daquilo que diz.

Para tanto, em termos práticos, foram apresentados à turma exemplos inspiradores de trabalhos desenvolvidos no Profletras-Unemat Cáceres acerca de intervenções nas quais é proposta a criação de arquivos de leituras com o intuito de que o sujeito-aluno possa estabelecer relações intertextuais e interdiscursivas, tendo em vista um tema apresentado em sala de aula. Nesse processo, são oferecidas condições para que esses alunos tornem-se sujeitos do que diz, bem como percebam a multiplicidade de sentidos que circulam na sociedade, em certas instituições, fora e dentro da escola (SANTOS; SARIAN, 2018).

\section{MOMENTO 2: NO JOGO ENTRE O ESTABILIZADO E O DIFERENTE}

Como já foi dito, ao contemplar as condições do texto $A$ carne, de Verissimo, foi muito produtivo o movimento de trabalhar em meio à memória que convoca sentidos anteriores e exteriores e ao mesmo tempo atualiza sentidos.

Nesse caso, não estamos tomando a memória como psicológica, mas, segundo Pêcheux (2010, p. 56), como "um espaço móvel de divisões, de disjunções, de deslocamentos e de retomadas, de conflitos de regularização".

Com efeito, ao mobilizar conceitos discursivos, houve um movimento produtivo de uma noção puxar a outra $e$, nesse caso, os processos de paráfrase (sedimentação de um sentido evidente) e de polissemia (mexida na memória, 
possibilidade de ser outro) permitiram contemplar a produção de sentidos na/pela memória do dizer.

Diante do exposto, seguem alguns exemplos de práticas de leitura que foram propostas/sugeridas para que fosse mobilizada a relação paráfrase e polissemia na disciplina "Linguagem, práticas sociais e ensino", com base no texto $A$ carne:

- Discussão sobre as diferentes condições de produção de ocorrência da expressão "carne fraca";

"Carne fraca" é um produto de má qualidade;

"Carne fraca" é o nome da operação da Polícia Federal que investigava o escândalo; "Carne fraca" é a propensão ao pecado e ao crime;

Nesse exemplo de prática de linguagem, nos perguntamos: como a expressão "carne fraca" significa diferentemente quando enunciada em diferentes condições de produção? Em meio a um espaço de discussões, foi enfatizado que a significação não está colada às palavras, mas que depende dos discursos em que os enunciados ocorrem. Desse modo, buscamos pensar em outras palavras que também significam diferentemente a cada condição de produção. Sugestões apresentadas foram "liberdade", "família" e "terra".

Seguem algumas reflexões empreendidas:

- Compreensão de como os sentidos de "liberdade" para a mãe não são os mesmos para o filho, pois os sujeitos estão posicionados em lugares sociais diferentes, histórica e ideologicamente constituídos;

- Investimento nos sentidos em opacidade. Por exemplo, foi trabalhado com a palavra "família" que pode significar "grupo composto pelos pais, avós, ou apenas um deles, e seus descendentes naturais ou adotados residentes na mesma casa", em uma formação discursiva jurídica. Já, em uma formação discursiva econômicocomercial passa a significar "pessoas ligadas a uma empresa, em uma formação discursiva em que "família" tem sentido de "empresa/organização" ou mesmo em uma formação discursiva política, a palavra "família" ganha sentidos de clã ou dinastia- avô-pai-filho que se perpetuam no poder 
- Discussão sobre a palavra "terra", em sua equivocidade, que pode ter um sentido de patrimônio, luta ou lugar sagrado, dependendo das posições em jogo;

Desse modo, buscamos enfocar as condições de produção (domínio religioso e popular) em que a expressão "carne fraca" pode significar a fraqueza humana (erro, falha, bem como justificativa para a traição, para aceitar a "maracutaia" e as condições de produção do domínio jurídico em que a expressão passa a significar "crime de corrupção" que deve ser respondido e punido).

Nas palavras de (BOLOGNINI; PFEIFFER; LAGAZZI, 2009, p. 7), "o trabalho simbólico da leitura demanda uma interpretação ante interpretações possíveis". Desse modo, foi preciso trabalhar, também, em meio à tensão entre a unidade imaginária de uma interpretação e a polissemia constitutiva que permite outras leituras. De fato, considerar que a ambiguidade é produtiva em processos de significação demanda dar escuta aos diferentes sentidos que um enunciado pode assumir de acordo com a formação discursiva na qual é (re)produzido.

Com efeito, o professor pode abrir espaços justamente para questionar a evidência de um sentido único e transparente ligado a um imaginário de língua como código. Assim, tanto o aluno quanto o professor podem justamente dar escuta a sentidos que estão em opacidade e pensarem no que poderia ter sido dito e que foi rejeitado, mas que produz seus efeitos.

\section{MOMENTO 3: ENTRE AS FRONTEIRAS DE FORMAÇÕES DISCURSIVAS (DORAVANTE, FD): O SENTIDO PODE SER OUTRO}

Com efeito, justamente, por conta das fronteiras tênues entre formações discursivas que constituem 0 interdiscurso, foi trabalhado, no caso do texto " $A$ carne", de Verissimo que a expressão nominal "carne fraca" não pode ser tomada como se tivesse um sentido nela mesma, Pelo efeito metafórico, isto é, pelo percurso do sentido em diferentes FDs, "carne fraca" significada, em uma formação discursiva religiosa, como falha, propensão ao pecado, desliza para um sentido de crime/violação das leis, em uma formação discursiva jurídica, o que remete à formasujeito do capitalismo, responsável pelo que diz e faz, com seus direitos e deveres. 
Desse modo, examinar que diferentes efeitos de sentidos se produzem com/na inscrição de uma palavra em diferentes FDs foi um gesto necessário para trazer um olhar para a não transparência do dizer.

Ademais, foi relevante trazer à discussão o conceito de efeito metafórico (PÊCHEUX, 1990, p. 96). A metáfora, para Pêcheux, não é tomada como desvio ou substituição, mas sim como um deslizamento dos sentidos, como transferência- uma palavra por outra, na medida em que o sentido sempre pode se tornar diferente de si mesmo.

Consequentemente, os processos de paráfrase e polissemia e a noção de efeito metafórico, além de serem demandados nas reflexões, foram também inspiração para abordagens diversas de leitura. Nesse sentido, trago à cena alguns exemplos que os próprios alunos e alunas produziram em meio ao desenvolvimento de suas propostas discursivas de leitura:

1) por que foi possível dizer uma coisa e não outra? Assim sendo, destacamos o trabalho de Michelly Luteski que trouxe um meme digital sobre a tragédia do Titanic a partir do qual pudemos pensar a respeito do papel das condições de produção na produção de sentidos. Nesse caso, foi discutido como o meme reverbera um sentido de tragédia ligada ao naufrágio- inscrito na memória do dizer- ao mesmo tempo que o desloca. Desse modo, o enunciado verbal "Se o Titanic afundasse hoje" e a imagem do acidente do barco naufragando estão em tensão com a formulação visual de diversas pessoas fotografando a cena com seus celulares. O jogo entre salvar a cena/salvar a vida produz um efeito-ironia ligado às novas condições de uso da tecnologia em situações-limite.

2) As palavras não têm um sentido colado a elas mesmas. Vale citar o trabalho de Maria Elena da Silva sobre a crônica "Gratidão de Assírio", da autoria de Lima Barreto. O gesto analítico empreendido permitiu dar escuta aos sentidos em opacidade, visto que uma expressão não tem um sentido preso nela mesma, mas precisa ser tomada com base na filiação a diversas formações discursivas tais como: a jurídica, a econômica, a política. Nesse caso, nos pautamos na palavra "voto" que, na crônica significava tanto o "dever cívico" quanto "troca de favores";

3) Os sentidos deslizam entre as fronteiras tênues das formações discursivas. Um trabalho a ser citado é o de Thais Moraes Sacchi que contempla os sentidos de 
"diário íntimo" que deslizam de "pessoal" para "público" e os movimentos de deriva, em uma prática sobre a temática do bullying, entre "produzir uma escrita de si no diário pessoal" e "a publicização da opinião no vlog ou vídeo-blog".

\section{UM POSSÍVEL FECHO}

Primeiramente, acreditamos na relevância de uma disciplina no quadro do Profletras na qual sejam discutidos aspectos ligados a uma abordagem discursiva de leitura em sala de aula. Justamente pelo fato de a Análise de discurso abrir-se para a escuta das possibilidades de sentidos a depender da inscrição em formações discursivas ou mesmo em diferentes condições de produção de leitura.

Segundo, diante de toda a complexidade de implementar práticas escolares reais e contextualizadas, foram trazidos alguns pontos nodais durante 0 desenvolvimento da disciplina: (a) as práticas de linguagem não devem se restringir somente à materialidade linguística do texto, mas precisam contar com a análise das condições de produção, da memória, do já-dito; (b) a produção da linguagem se assenta em dois processos tensos: a paráfrase e a polissemia; (c) a autoria se produz quando o sujeito filia-se a sentidos e se sente seguro para dizer o que diz.

De fato, a construção de um caminho para uma abordagem discursiva de textos, na disciplina "Linguagem, práticas sociais e ensino", possibilitou clarificar a importância das condições de produção dos sentidos e a força dos processos de paráfrase e polissemia em práticas de leitura de materialidades diversas, contemplando tanto as significações estabilizadas quanto os deslizes de sentido. Enfim, reiteramos que a proposta discursiva mostra-se produtiva justamente por deslocar uma visão conteudística dos sentidos, bem como possibilitar a efetivação da autoria em aulas de Língua Portuguesa.

\section{REFERÊNCIAS}

BOLOGNINI, C. Z.; PFEIFFER, C.; LAGAZZI, S. Discurso e Ensino: Práticas de Linguagem na Escola. Campinas: Mercado das Letras, 2009.

HASHIGUTI, S. T. Nas teias da leitura. In: BOLOGNINI, C. Z. (org.). Discurso e ensino: prática de linguagem na escola. Campinas: Mercado de Letras 2009. p. 1929 
LAGAZZI, S. A equivocidade na circulação do conhecimento científico. Linguagem em (Dis)curso, v. 11, n. 3, Palhoça, p. 497-514, 2011.

FERREIRA, M. C. L. O quadro atual da Análise de Discurso no Brasil. In: Revista Letras, n. 27, Santa Maria, p. 39-46, 2003.

MALDIDIER, D. A inquietação do discurso: (re)ler Michel Pêcheux hoje. Tradução de Eni Orlandi. Campinas: Editora Pontes, 2003.

ORLANDI, E. Análise de discurso. Princípios e procedimentos. Campinas: Pontes, 1999.

ORLANDI, E. Discurso e leitura. 9. ed. Campinas: Pontes, 2012.

ORLANDI, E. Discurso e texto: formação e circulação dos sentidos. Campinas: Pontes, 2001.

PÊCHEUX, M. Análise Automática do Discurso: (ADD-69). In: GADET, F.; HAK, T. (org.). Por uma análise automática do discurso: uma introdução à obra de Michel Pêcheux. Campinas: Unicamp, 1990. p. 61-161.

PÊCHEUX, M. O papel da memória. In: ACHARD, P. et al. O papel da memória. Tradução de José Horta Nunes. 3. ed. Campinas: Pontes, 2010. p. 49-57

PÊCHEUX, M. Semântica e Discurso. Uma Crítica à Afirmação do Óbvio. Tradução de Eni P. de Orlandi et al. Campinas: Editora da UNICAMP, 1988. Publicado originalmente em 1975.

PFEIFFER, C. R. O leitor no contexto escolar. In: ORLANDI, E. P. (org.). A leitura e os leitores. 2. ed. Campinas: Pontes, 2003. p. 87-104.

SANTOS, M. J.; SARIAN, M. C. Das injunções institucionais à constituição da autoria: uma via para o trabalho com a leitura e a escrita na escola. Investigações (online), v. 31, Recife, p. 339-367, 2018.

VERISSIMO, L. F. A carne. In: O GLOBO. [S. I.], 23 mar. 2017. Disponível em: https://oglobo.globo.com/opiniao/a-carne-21100553. Acesso em: 23 maio 2017. 


\section{Sobre a autora}

\section{Luciana Cristina Ferreira Dias Di Raimo}

Professora associada lotada no Departamento de Língua Portuguesa (DLP), da Universidade Estadual de Maringá (UEM). Atua na graduação em disciplinas de Oficina de leitura e produção de textos e Estágio supervisionado. Atua no Programa de Pós-graduação do Profletras-UEM no qual atualmente é coordenadora. Tem doutorado em Linguística Aplicada pela Unicamp, mestrado em Letras (área de concentração: Filologia e Linguística Portuguesa) na Unesp-Assis, e formação em Letras pela Unesp-Assis. As pesquisas desenvolvidas e por ela orientadas giram em torno de propostas e implementações de práticas de leitura e escrita em um viés discursivo com base em materialidades diversas. Além disso, tem se dedicado a publicar trabalhos sobre propostas e intervenções em sala de aula cujo propósito é o de fomentar a autoria nas práticas em sala de aula e possibilitar que os sujeitos-leitores produzam outros gestos de leitura além de um sentido autorizado pelo professor ou pelo livro didático. 